\title{
Sob o Signo DO DIÁLOGO
}

\author{
RELATO DE EXPERIÊNCIA: \\ PROJETO SÃO PAULO DE PERFIL
}

CENA 1: Um policial acabara de ler Vozes da Crise, o segundo livro-reportagem da série São Paulo de Perfil e, entusiasmado, perguntou ao professor de português - "Eu queria ler mais um desses livros, o senhor pode me emprestar?'” O professor ficou surpreso, afinal, um PM do segundo grau noturno tão interessado assim em leitura... Não se conteve: "Você gostou do livro?" "Gostei muito, professor. Sabe de uma coisa? Com esse livro, eu que conheço muito bem o lado da polícia, aprendi como são as pessoas do outro lado". (São Paulo, 1990)

Cena 2: Dez anos antes da cena acima narrada, um jornalista norte-americano mostrava um conjunto de pequenas brochuras que contavam a história oral de personagens anônimos novaiorquinos. Cansado da vida na grande imprensa, Arthur Tobier se agregou, já em plena maturidade profissional, a um grupo de artistas do East Side (Lado Leste) e começou a escrever uma série de histórias de personagens da cidade que jamais chegariam à consagração nos meios de comunicação ou nos documentos oficiais. Cada livrinho, subsidiado por uma fundação, era incorporado como leitura de história imediata na rede de escolas do East Side de Nova York.

\section{A AUTORA}

Cremilda Medina

Jornalista, pesquisadora e professora titular da Universidade de São Paulo.

Criadora e responsável pelo Projeto São Paulo de Perfil no curso de graduação de Jornalismo da Escola de Comunicações e Artes.

Professora na Pós-Graduação de Ciências da Comunicação da ECA e do Programa Latino-Americano da USP, tem vários livros publicados, entre eles: Notícia, um Produto à Venda (Summus Editorial) e Profissão Jornalista, Responsabilidade Social (Forense). 
Ou seja: os meninos da periferia do grande mundo moderno e capitalista, hispanos em grande parte, se identificavam com os heróis (anti-heróis) que regem a luta do cotidiano. $\mathrm{Na}$ era Reagan, com corte dos subsídios artísticos e culturais, o projeto desapareceu.

(Nova York, 1980)

As duas cenas se entrelaçam na gênese e definição do Projeto São Paulo de Perfil, que criei na Universidade de São Paulo. Quando passava por Nova York, em janeiro de 1980, a série do parceiro de desgostos gerados na grande imprensa caiu fundo no meu inconsciente. Ainda batalhava intensamente no jornalismo diário, sobretudo porque se vivia, no Brasil, a construção da abertura ou redemocratização. Numa editora de artes e cultura de um jornal influente, a equipe por mim coordenada se lançava com paixão e convicção à luta contra a censura, contra o cerceamento de atos e idéias, emprestava as técnicas de comunicação à voz coletiva e às vozes corajosas dos artistas, que organizavam caravanas a Brasília. Esse espaço jornalístico cobria com fervor os movimentos rebeldes. Tal força-motriz se expande coletivamente até 1984, com as Diretas-Já. A derrota, em abril desse ano, coincide com a quebra do tônus criativo no trabalho profissional. As empresas jornalísticas, então voltadas para a modernização tecnológica (a era da informatização), passam a tolher o que de forma quase orquestrada consideram, então, ímpetos esquerdistas. Perdem-se ou se atrofiam os projetos sociais e sobem ao estrelato projetos técnico-formais, como, por exemplo, os recursos de computação gráfica, a fórmula da notícia curta, descarnada, os gráficos de superfície sobre os comportamentos humanos.

Em estado de insatisfação e inquietude deixei o jornalismo diário em 1986 (aí me iniciara em 1963). A decisão se formou gradualmente e voltei à Universidade de São Paulo de onde saíra, na repressão, em 1975. Com o doutoramento nesse mesmo ano, delineou-se não a Idade da Razão segundo as Luzes, mas a Idade da Emoção segundo o Hemisfério Sol ou a aventura do Hemisfério Direito fertilizando o Hemisfério Esquerdo. A tese de doutorado - Modo de Ser, Mo'Dizer - não rezou segundo a cartilha ortodoxa da angústia acadêmica, mas se pautou pela humanização. $O$ Diálogo Possivel ${ }^{1}$ (título da segunda parte da tese) pode traduzir um projeto de pesquisa para efeitos formais, mas, para além da Ciência Normal de Thomas $\mathrm{Kuhn}^{2}$, é uma busca profundamente enraizada no que preservei de humano na caminhada técnica e profissional.

Surge assim a Série São Paulo de Perfil que, adotando o suporte livro, veicula a grande reportagem. Esboça-se então um projeto de reconstituição do rosto do "monstro", esse rosto multifacetado de Brasil, de mundo contemporâneo e de tribos locais. Hoje são 14 livros publicados e mais um em edição (julho de 1994). Rigorosamente uma edição por semestre letivo. O projeto começa, de imediato, com objetivos assentados no tripé ensino, pesquisa e extensão, não se podendo desvincular uma da outra finalidade. $O$ processo se alimenta dessa complexidade e a experiência (aci- 
dentada) de 1987 a 1994 atesta, através de documentos, sinais e convênios, que formar novos jornalistas, pesquisar a linguagem dialógica e receber o retorno de uma recepção ativa fora da Universidade são pilares hoje muito concretos.

A propósito, vem agora a primeiro plano o depoimento de uma jornalista, ex-aluna do Projeto:

Cena 3: "Hoje eu não sou mais uma estudante. Faço parte do mercado de trabalho cada vez mais estreito, à procura de gente criativa, com novas idéias, com vontade de fazer jornalismo. E é exatamente aí que o Projeto São Paulo de Perfil age. Ele abre uma janela que vai além dos limites estabelecidos. Incentiva a criatividade do futuro jornalista e desperta o interesse pelo leitor. Qual o jornalista que consegue ver a cara de seu leitor, ouvir sua voz, críticas e elogios? Se eles existem, com certeza são raríssimos. O projeto possibilita o diálogo entre escritor e leitor. Um diálogo enriquecedor para ambas as partes".

(Patrícia Teixeira, São Paulo, 1994)

A linguagem dialógica, ou o signo da relação, norteia o projeto pedagógico que venho desenvolvendo, primeiro, no ensino de segundo grau (de 1964 a 1967), posteriormente, no ensino superior (de 1967 a 1970 na Univerisdade Federal do Rio Grande do Sul, de 1971 a 1975 bem como de 1986 até hoje na Universidade de São Paulo). Já desde minha formação didática pelo curso de Letras, que completei junto com o curso de Jornalismo na Universidade Pública do Rio Grande do Sul, a prática do diálogo social me seduziu.

No exercício do Jornalismo elegi como prioridade a prática do repórter como um mediador social dos discursos da atualidade.

Era inevitável que os mais recentes planos de trabalho se inspirassem na pesquisa de signo interacionista.

Venho observando através de experimentos pedagógicos que o aluno de Jornalismo (trabalho com o terceiro ano de um curso que se desenvolve em quatro no matutino e cinco no noturno) chega às disciplinas Redação Jornalística II - Oralidade e Redação Jornalística III - Interpretação (no novo currículo de Jornalismo serão mais apropriadamente denominadas Teoria da Reportagem I e II) com certas atrofias que impedem a criatividade de que fala Patrícia Teixeira. A formação técnica do jornalista se sintoniza com a escolarização de uma maneira geral que, por sua vez, se sintoniza com as ênfases da cultura da modernidade: a racionalidade esquemáticoburocrática se sobrepõe às virtualidades criativas e às estratégias transformadoras. A partir de resultados colhidos ao longo dos últimos oito anos que reforçam teorias como a da Cibernética Social ${ }^{3}$, a oficina pedagógica tem mobilizado a ressensibilização do hemisfério direito, ou as forças emotivo-intuitivas, e a aceleração de ações (no caso, através da reportagem) criativas. 
No fundo, a pedagogia de um novo jornalismo se alimenta do prazer e do desejo que se associam ao pensar sistemático e se expressam no fazer.

Este é um capítulo à parte que um dia poderá ser abordado nesta Revista. A experiência, no entanto, não se inscreve no experimentalismo gratuito ou sedento de modismos teóricos. Vale a pena recuperar aqui um depoimento em veículo sindical onde testemunho o longo percurso da pedagogia.

Cena 4: "No projeto de formação de jornalistas que pesquiso desde 1967, quando fui convidada a trabalhar como docente na Universidade Federal do Rio Grande do Sul, tem sido cada vez mais oportuno enfrentar a complexidade ao mesmo tempo ética, técnica e estética. A História do Jornalismo põe em evidência os impasses morais; a tradição profissional acumula, para além das facilidades tecnológicas, os desafios técnicos; e os grandes autores mostram o significado social das inovações estéticas.

Ora, em ambientes pedagógicos - mais favoráveis na universidade pública, mas também em instituições privadas sérias - é possível desenvolver essas aptidões conjuntamente, observando e motivando uma oficina permanente. Para isso tenho me valido de fundamentos que progressivamente vêm recebendo contribuições de várias áreas do conhecimento científico, da arte e de outras sabedorias humanas. As informações hoje à disposição do estudioso no que tange à complexidade cerebral, oferecem subsídios inestimáveis ao ensino de Jornalismo. Lidar, então, com as virtualidades lógico-analíticas, intuitivo-sintéticas e motor-operacionais fertiliza a capacitação profissional. No mínimo, este laboratório desperta os vínculos indissociáveis da ética com a técnica criativa.

Dito desta forma parece abstrato. Concretize-se, porém, nas práticas profissionais da pauta à execução e retorno de determinada matéria. As fórmulas de trabalho - as que informam o aprendiz de feiticeiro - pecam por esquematismo tanto no que se refere às decisões éticas quanto no que se refere à inventividade estética. Aplica-se o modelo mental quem, o quê, quando, onde, como e por quê, equaciona-se a notícia através de um "lead sumário" (abertura de matéria jornalística) e narra-se um fragmento da História através da pirâmide invertida. Aparentemente esta técnica e suas variantes próximas, já impregnada na memória profissional, é um sucesso histórico a partir do século XIX. Estão aí as agências de notícias que a consagraram no planeta. No entanto, qualquer situação-limite da humanidade - tome-se, por exemplo, a Guerra do Golfo Pérsico - provoca nos jornalistas lúcidos e nos analistas uma angustiada reflexão a respeito das insuficiências da herança e da modernização técnica e tecnológica. Esta gramática jornalística não dá conta das demandas coletivas de acordo com parâmetros éticos universais. 
Mostra-se também frágil uma ética rigorosamente regida por preceitos, códigos, normas de conduta. A busca racional de tais princípios marca a trajetória do pensamento ocidental dos gregos a Jürgen Habermas, para citar apenas um contemporâneo de peso. $O$ problema que se propõe: a moralidade, no seu caráter universal, e as atitudes éticas de cada cultura não passam exclusivamente pela racionalidade lógico-analítica. Passam, sobretudo, pelo desejo que se expressa através de profundas intuições. O gesto moral explode dos afetos, da sintonia solidária com o inconsciente coletivo. Estão aí os artistas que compreendem como ninguém os motes da aventura humana e criam a linguagem dos desejos.

$\mathrm{Da}$ interregulagem dos poderes do hemisfério direito do cérebro (ao que tudo indica, mobilizador das sínteses criativas) e do hemisfério esquerdo (responsável pela racionalidade) se desencadeiam estratégias operacionais sensíveis e competentes. O empobrecimento técnico-ético-estético dos ambientes empresariais não proporciona condições de aperfeiçoamento ao estudante ou ao estudioso de Jornalismo. Daí a oportunidade da pesquisa e do ensino universitário.

Em Moçambique, um poeta africano me confessou: 'Ainda não me sinto digno de escrever sobre meu povo. Preciso crescer para estar à altura de narrar a saga coletiva.' Quem sabe essa não é uma boa inspiração para os jornalistas".

(Cremilda Medina, jornal Unidade, do Sindicato de Jornalistas de São Paulo, junho/1994)

A série São Paulo de Perfil, ao começar em 1987, ainda não tinha uma política de pautas definida. Os alunos de terceiro ano de Jornalismo se lançavam em uma zona de risco - a re-humanização das pautas, a reportagem de aprofundamento, a busca de identidade cultural, a compreensão do cotidiano, dos tempos e dos espaços da atualidade brasileira, paulistana e paulista. $\mathrm{O}$ final de semestre culminaria com um produto coletivo, um livro-reportagem monotemático. $\mathrm{O}$ gancho de atualidade em 87 era o da Constituinte e assim se decidiu a pauta do Virado à Paulista, que reuniu o perfil de dezessete constituintes por São Paulo. O lançamento, já no ano da Constituição, 1988, culminou com um debate no estúdio de rádio do Departamento de Jornalismo e Editoração da ECA e logo depois veiculado pela Rádio USP. Ao debate, compareceram deputados que faziam parte do livro. Este exemplar perfeitamente datado tem causado surpresa quando, em anos de eleições, volta a cartaz em programas educacionais e alguns professores requerem a presença dos alunos-autores em classe. Os que escreveram os primeiros e até os mais recentes já estão perfeitamente inseridos no mercado de trabalho e muitas vezes fica difícil convidá-los ao reencontro com suas crias numa sala de aula de segundo grau, em São Paulo ou fora da cidade.

A repercussão sentida através do primeiro livro da série e, sobretudo, do segundo - Vozes da Crise -, também realizado em 1987, projetou duas 
conseqüências: a série se definiu numa política editorial de dois grandes fôlegos - a) quem faz o perfil de São Paulo; b) quais os grandes enfrentamentos de quem vive e sofre a atualidade. Ou seja, uma família de pautas tem tateado os fluxos migratórios e diferenças culturais da mestiçagem brasileira, outra família de pautas procura reportar os desafios do contexto sócio-político-cultural da contemporaneidade. Fazem parte da primeira família os nordestinos, os hispano-americanos, os judeus, os índios, os italianos, os portugueses; na segunda família, vêm os temas que tentam compreender a crise, a rebeldia jovem, a habitação, a periferia urbana, a educação, o lazer ou a religiosidade 4 .

A outra definição que logo se configurou vai ao encontro dos significados da extensão universitária.

\section{A pesquisa da linguagem dialógica e projeto de formação de um novo jornalista mais criativo e eticamente competente precisaria de parâ- metros externos, informados pela recepção ativa.}

Procurei então (em 1988) a Comissão de Cultura e Extensão da USP, posteriormente uma das Pró-Reitorias, formulei um projeto de pesquisa e pedi bolsas de iniciação científica ao CNPq e tudo passou a fluir apesar dos tremores de terra do Brasil pós-morte de Tancredo. Nada como o depoimento de uma bolsista histórica, hoje jornalista e pós-graduanda em Ciências da Comunicação e Semiótica, às vésperas de ingressar na carreira diplomática:

Cena 5: "Penso no olhar carinhoso e moral da história. Em 1989, livros debaixo do braço, começamos as negociações com a Secretaria de Estado da Educação para um convênio de leitura, em sala de aula, do Projeto São Paulo de Perfil. Éramos, quase sempre, atropeladas por mudanças nos cargos diretivos, a licença ou as férias de funcionários com os quais tínhamos mantido negociação, a iminência de greves, crises orçamentárias. Resolvemos, então, investir experimentalmente em outra frente: um colégio particular de Primeiro e Segundo Graus, o São Vicente de Paula, na Penha (zona leste).

Optamos por alunos da segunda série do Segundo Grau, que ainda não viviam o desespero do vestibular nem tinham nostalgias do ginásio. Os alunos podiam optar por um dos três volumes da série - Vozes da Crise, Nos Passos da Rebeldia, Forró na Garoa -, vendidos a preços reduzidos. Depois, faziam um comentário da leitura por escrito que nós - e os professores de Língua Portuguesa - analisávamos.

Algumas surpresas: a maioria dos estudantes decidiu ler os três livros. Em suas leituras, três aspectos eram muito fortes:

- A sedução da linguagem e dos temas - muitos deles destacaram sérias desavenças, em suas histórias escolares, com a leitura de clássicos, de 
obras recomendadas pelos professores. Jornais e revistas, achavam chatos. Mas os livros... eram, para eles, rápidos de ler, bonitos e diferentes.

- A solidariedade de um olhar carinhoso - Jovens da classe média, moradores de um bairro periférico, eles estavam na incômoda proximidade da pobreza, sem serem pobres. Uma posição muito propícia ao desenvolvimento de preconceitos. O choque de ver o outro - o nordestino, o morador de rua, o estudante com militância acadêmico-partidária tratado com carinho foi uma iluminação para aqueles jovens e também para mim (como profissional, desenvolvi, a partir daí, uma grande preocupação em captar o outro onde ele se encontra, em não macular sua dimensão histórica pessoal).

- A desmontagem da moral da história - Mergulhados nos textos, os nossos jovens rapidamente captaram uma diferença: não havia moral da estória - tão comum em livros didáticos. Eles estranharam que nem sempre os finais eram 'justos', que os personagens sentiam as dores do acaso, que o grande imponderável dos sonhos e dos desejos não era suscetível à lógica. Desmontaram, ou começaram a desmontar, a mentalidade de causas e consequiências, de atos e efeitos, de simplificação humana".

(Elen Geraldes, jornalista, ex-bolsista do Projeto São Paulo de Perfil, 1994)

A institucionalização do projeto na Secretaria de Educação do Estado de São Paulo talvez seja o capítulo mais doloroso da experiência. Não por motivos pedagógicos ou culturais, mas por questões burocráticas e financeiras. A saga brasileira conhece profundamente estes obstáculos. Os livros da Série São Paulo de Perfil são impressos na gráfica da Escola de Comunicações e Artes e representam, no orçamento de projetos e laboratórios do Departamento de Jornalismo e Editoração da Universidade de São Paulo, a parcela menor, quer dizer, onze mil reais por ano, cinco para cada edição de mil a mil e quinhentos exemplares (de 1993 em diante) por semestre e mil reais para outras despesas. Mas desde os dois primeiros anos havia a preocupação de tornar o projeto auto-sustentado. A venda avulsa, a preço de custo, escoava uma boa parte da tiragem (metade em geral), mas sem suporte comercial convencional. Os livros, vendidos na ECA e numa venda de mão em mão (em geral dos autores de cada par de livros), não estão respaldados até hoje, oito anos depois de implantado o projeto, por um suporte de distribuição e comercialização.

Quando se impôs o projeto de extensão junto às escolas de segundo grau no ensino público era preciso encontrar um subsídio, um patrocinador. Definiu-se a cota de 500 exemplares para abastecer a $16^{\mathrm{a}}$ Delegacia de Ensino que, por sua vez, delimitou 16 escolas para serem atingidas. Foram também incluídos na experiência três CEFAMs (Centros Específicos de Formação e Aperfeiçoamento do Magistério). Sensibilizado pelo projeto, José Mindlin facilitou um patrocínio da "Metal Leve" que passou a comprar, entre $1990 \mathrm{e}$ 
1992, 500 livros para este convênio. Aí então desenvolveu-se uma leitura na escola de segundo grau que outra jornalista acompanhou à época.

Cena 6: "“A dor da gente não sai no jornal', canta Chico Buarque em uma de suas músicas. De fato, boa parte da imprensa tem se orientado por uma linguagem burocrática e fria, distante de seus protagonistas. As pessoas não se reconhecem nas notícias porque o relato carece de humanidade. $O$ que pude avaliar no acompanhamento da receptividade de alunos de segundo grau que lêem os livros-reportagem do São Paulo de Perfil, sob a orientação dos professores responsáveis, é uma dinâmica muito rica. As classes se dividem em grupos, cada um escolhe um livro, promovem-se depois debates dos quais eu participei e uma avaliação por escrito (que consta da documentação do projeto na USP). Entre as conclusões que a experiência tem possibilitado, pode-se destacar a familiaridade que os alunos apresentam em relação aos temas abordados. Muitos se identificam com as situações narradas e partem espontaneamente para outras leituras. Também escolhem personagens, na realidade pessoas localizadas pela reportagem, como se fosse uma dramatização do próprio eu ou de um familiar, um conhecido". Perfil)

(Tânia Sandroni, jornalista, ex-bolsista do Projeto São Paulo de

A travessia da experiência nunca foi tranquiila.

Os estudantes de Jornalismo da ECA, ao se confrontarem com um plano de curso muito desafiador se iniciam, antes mesmo de chegar ao terceiro ano, em conflito interno que vai da rejeição à adesão apaixonada.

As dinâmicas de grupo são muito sofridas e vale, pedagogicamente, o acompanhamento corpo a corpo numa pasta de produção semanal e uma conversação constante. O embate é o mais delicado possível: transitar do conforto das fórmulas de manual jornalístico para a criação de formas diversificadas segundo o grau de compreensão complexa das situações sociais, de seus protagonistas e de entrega criativa do jornalista. Inverter a relação sujeito-objeto do técnico para a relação sujeito-sujeito, para além de ser um problema epistemológico ${ }^{5}$, é uma fogueira que queima as certezas, as rotinas profissionais, o ritmo mecânico do exercício jornalístico.

Mas as dificuldades vão adiante na produção gráfica do livro no âmbito da universidade. Os gráficos da ECA se apaixonaram pelo projeto e essa é a principal força que faz superar os clássicos entraves que todos conhecem em qualquer espaço público de produção de livros. $\mathrm{O}$ empenho e a afeição têm dado, ao longo de oito anos, uma marca cada vez mais identificatória do projeto também no grafismo, capas, tratamento visual. A tal ponto que em junho de 1994, num encontro no Sindicato dos Jornalistas do Mato Grosso, o exemplar número 14 da série - Nau dos Desejos - foi elo- 
giado: "Parece um livro feito pela Companhia das Letras". Mal sabe esse jornalista que doloroso parto, a cada semestre, põe em pé o livro, ultimamente beirando às 300 páginas impressas.

Sofridas são as negociações para dar continuidade à extensão. Em 1993, no contexto recessivo, a "Metal Leve" suspendeu o patrocínio. Uma vez mais se chegou à Secretaria de Educação do Estado de São Paulo para discutir o impasse e Fernando Moraes, Secretário então, imediatamente compreendeu a situação, embora as primeiras aproximações (1989) tenham ocorrido em outra gestão. Provavelmente como jornalista ele tenha percebido a filosofia do projeto sem nenhuma lentidão burocrática. De pronto assumiu a responsabilidade de comprar, por meio da FDE (Fundação para o Desenvolvimento da Educação), mil livros - quinhentos a mais - para expandir o projeto para a rede de escolas-padrão. Assim aconteceu com o livro da migração italiana, o $12^{\circ}$ da série, Tchau Itália Ciao Brasil. Entretanto, mudou o Secretário, mudaram as chefias e, em 1994, vive-se um novo impasse. As negociações recomeçam tal qual o mito do eterno retorno. $\mathrm{O}$ incrível é não haver obstáculos no ambiente próprio da leitura dos livros. Pelo contrário, os professores da $16^{\mathrm{a}}$ Delegacia continuam trabalhando com os livros, como relata a atual bolsista.

Cena 7: "O entusiasmo de professores e alunos da $16^{\mathrm{a}}$ Delegacia de Ensino de São Paulo em relação ao projeto é gratificante e chega a surpreender. Para os leitores, a série São Paulo de Perfil é 'um exemplo alunos como nós escreverem um livro bem elaborado, informativo' (turma do segundo colegial - EEPSG 'Henfil', a respeito de A Escola no Outono, $9^{\circ}$ livro da Série).

Os livros-reportagem não só servem como material de apoio e enriquecimento para a formação dos alunos (isto já é bastante), mas também para a construção da cidadania de todos os leitores. O professor de Sociologia da EEPSG 'Henfil' trabalhou com os alunos A Escola no Outono, sobre educação, e aprendeu com a leitura: 'Há informações ali que nem os professores têm acesso'. No segundo semestre de 1994, o professor Cido quer desenvolver um trabalho no 'Henfil' sobre as religiões e Guia das Almas, o $13^{\circ}$ livro da Série, será utilizado como estímulo à pesquisa e fonte de consulta.

Os alunos no princípio desanimam diante dos volumes grossos, de mais de duzentas páginas - e se nem professores têm tempo de ler, que dirá os alunos. A Série São Paulo de Perfil oferece algumas dificuldades à leitura mas para os alunos não é um livro de obrigação, como os de literatura. $O$ fato de ser feito por estudantes motiva mais. $O$ professor de redação Norberto Nogueira (EEPSG 'Brasílio Machado') desenvolveu trabalhos com vários números da Série São Paulo de Perfil e acredita que o texto pessoal dos alunos cresce com a leitura dos livros-reportagem. 
Tanto professores como alunos da $16^{\mathrm{a}}$ Delegacia de Ensino de São Paulo gostam e pedem as visitas dos jovens repórteres às escolas, como aconteceu na escola 'Henfil'. Ver quem faz e como se faz um livro desperta o interesse dos alunos.

O professor Ílio, um dos coordenadores na $16^{\mathrm{a}}$ Delegacia de Ensino, acha que os livros da Série São Paulo de Perfil têm qualidade e conteúdo informativo suficiente para serem indicados para a lista da Fuvest. É claro que para isso seria necessário expandir o projeto de forma ambiciosa; mas depoimentos como esse compensam toda a luta e esforço necessários para levar o São Paulo de Perfil à sala de aula".

(Patrícia Patrício, atual bolsista de iniciação científica do Projeto São Paulo de Perfil, 1994).

Não posso deixar de registrar que esta experiência em processo (insisto, doloroso) conta também com dois reencantamentos. Os próprios profissionais do mercado manifestam aqui e ali a compreensão e a legitimaçāo da proposta dialógica, criativa e ética da nova linguagem jornalística. Ao longo dos últimos oito anos colecionou-se uma série de recortes de imprensa e registros em espaços de rádio e de televisão por ocasião dos 14 lançamentos, sempre fora da Universidade, amarrados a eventos junto às comunidades-sujeito do livro. Mas além da chamada divulgação e do valor que se dá à mídia consagrada,

permanecem na memória do projeto confissões particulares de jornalistas que manifestam o desejo de praticar esse tipo de reportagem. Frequientemente colaboram nos livros porque aí realizam sua integridade profissional.

Um desses jornalistas não se aplacou na confissão tímida e levou às conseqüências finais sua conviç̧ão, escrevendo e publicando no Jornal do Brasil de 9 de agosto de 1990 que o volume $A$ Casa Imaginária $\left(6^{\circ}\right.$ da série, sobre habitação) resgata uma linguagem humanizadora, tratando com detalhes e emoção o cotidiano das pessoas que frequientam os jornais como simples números do problema habitacional.

No meio especializado das fontes científicas, o projeto tem tido uma cooperação muito rica e diferenciada. Normalmente o jornalista encontra resistências entre os especialistas. O Projeto São Paulo de Perfil implantou solidamente uma relação entre a construção de cada pauta e os consultores especializados. Assim, quando se discutiu como abordar o lazer em São Paulo, realizaram-se verdadeiras terapias de grupo com psicólogos para tentar compreender as implicações mais íntimas do lúdico. Dessas reuniões desconstrutivas da pauta óbvia se partiu para a reportagem com uma especulação profunda: o lúdico enquanto ato emancipatório. Daí o título do livro Farra Alforria ( $11^{\circ}$ da série). 
A voz especializada tem sido fundamental na vertente da reportagem que colhe diagnósticos e prognósticos das situações temáticas dos livros. Ora essa voz assume o papel tradicional de fonte de informação ou colaborador-ensaísta, ora é um permanente alter-ego do repórter que cultiva a pesquisa junto aos especialistas. Já ocorreu, porém, uma conquista inédita no Jornalismo. Na pauta da periferia que se consuma no $8^{\circ}$ livro - $\grave{A}$ Margem do Ipiranga -, Lúcio Kowarick, sociólogo da USP, procurado para escrever um texto sobre o tema, procedeu de uma forma pioneira. Montou o ensaio "Periferias e subcidadania", que abre o volume, articulando dialogicamente o texto de autoria especializada com a reportagem. Pediu textos de reportagem ainda em original e buscou nesses textos vozes vivas da periferia (cada repórter trabalhou em um ponto extremo do município de São Paulo) que dessem aval às afirmações sociológicas. Este triálogo possível - protagonista da ação social, mediador-jornalista e articulista - abriu um horizonte em que se deve investir no Jornalismo.

Tantas as possibilidades, tantas as dificuldades que não se pode ceder nem ao desânimo nem à euforia. $O$ fato é que a cada recomeço uma situação fica clara:

vive-se a emergência da comunicação e emergente se faz a construção do signo da interação social transformadora.

A dificuldade mais substantiva se expressa no conflito dos diferentes e a arte de tecer interregulagens. Os problemas são políticos e econômicos, mas também culturais. Qualquer experiência interativa semeia tempestades na visão de mundo estratificada das profissões modernas. O Projeto São Paulo de Perfil nasceu nessa inquietude, chega agora ao oitavo ano de esforço coletivo e está mergulhando no 150 desafio - o centro da cidade. Encontraremos no microcosmo do "centrão" alguns novos significados para a próxima jornada? Em O Guia das Almas (13o), ao sondar a subjetividade, o desejo mais íntimo, aprendemos a respeitar a linguagem religiosa que subjaz à luta cotidiana. De lá para cá não foi nada fácil, mas a energia da fé se justapôs ao desgaste da erosão. A sobrevivência de qualquer projeto está diretamente vinculada à dinâmica do caos.

\section{NOTAS E BIBLIOGRAFIA}

1. Título de um livro: Entrevista, o diálogo possível. São Paulo, Ática, 1986 (extraído da tese de doutoramento, Modo de Ser, Mo'Dizer).

2. KUHN, Thomas. A Estrutura das revoluções científicas. São Paulo. Perspectiva, 1989.

3. A Cibernética Social é uma proposta transformadora aplicável à Educação, à Comunicação e às Ciências Humanas. Dois dos principais autores fixaram em livro essa formulação:

GRECO, Milton. A aventura humana entre o real e o imaginário. 2. ed. São Paulo, Perspectiva, 1984. 
Interdisciplinaridade e revolução do cérebro. 2.ed. São Paulo, Pancast Editora, 1994. GREGORI, Waldemar de. Cibernética social I e II. 2. ed. São Paulo, Perspectiva, 1988.

4. A série São Paulo de perfil é composta das seguintes edições, por ordem cronológica:

Virado à Paulista (1987), memória de 17 constituintes por São Paulo; Vozes da Crise (1987), relatos populares que interpretam a crise brasileira; Nos Passos da Rebeldia (1988), três décadas de movimentos estudantis; Forró na Garoa (1988), histórias de nordestinos em São Paulo; Hermanos Aqui (1989), a saga dos hispano-americanos na Paulicéia; A Casa Imaginária (1989), problemas habitacionais e representações simbólicas de lar; Paulicéia Prometida (1990), história de judeus que chegaram ao planalto; À Margem do Ipiranga (1990), o cotidiano nos extremos da metrópole; A Escola no Outono (1991), o sonho de uma primavera na educação; O Primeiro Habitante (1992), mitos e lamentos do índio; Farra Alforria (1992), como São Paulo brinca; Tchau Itália, Ciao Brasil (1993), histórias de vida dos italianos; Guia das Almas (1993), vivências religiosas na terra de Anchieta; Nau dos Desejos (1994), a viagem secular do imigrante português.

Estes livros se encontram à venda no Departamento de Jornalismo e Editoração da Escola de Comunicações e Artes da Universidade de São Paulo, rua Prof. Lúcio Martins Rodrigues, 443, Cidade Universitária Armando de Salles Oliveira, CEP 05508-901, São Paulo-SP.

5. MEDINA, Cremilda. Jornalismo e a Epistemologia da Complexidade, in Novo pacto da Ciência, $A$ crise de paradigmas, MEDINA, Cremilda (org.), São Paulo, ECA-USP, 1992.

Depoimentos: Elen Geraldes, Patrícia Teixeira, Patrícia Sales Patrício e Tânia Sandroni 